\title{
Energy balance and formation of sun crust in snow
}

\author{
Toshiniro Ozeki, ${ }^{1}$ Eizi Akitaya ${ }^{2}$ \\ ${ }^{1}$ Department of Civil Engineering, Hokkaido University, Sapporo 060, Japan \\ ${ }^{2}$ Institute of Low Temperature Science, Hokkaido University, Sapporo 060, Japan
}

\begin{abstract}
The mechanism of sun-crust formation was investigated through laboratory experiments in a cold wind tunnel. The experiments were carried out by controlling the energy balance and the sun crust formed was consistent with that observed in Nature, i.e. a thin ice layer composed of ice particles and cavities due to internal melting beneath the sun-crust layer. The surface-cooling rate was between -50 and $-100 \mathrm{~W} \mathrm{~m}^{2}$, and the absorption of shortwave radiation exceeded $200 \mathrm{~W} \mathrm{~m}^{-2}$. The energy balance during the formation of the sun crust is consistent with the data observed in Nature.

The sources of $\mathrm{H}_{2} \mathrm{O}$ for the sun-crust formation were investigated through changes in $\delta^{18} \mathrm{O}$. Taking into account that the $\delta$ value of sun crust was larger than that of the snow beneath it and the calculations of the latent-heat emission with the sun-crust formation, it was concluded that the retention of meltwater by capillary force and refreezing in a thin layer was the dominant mechanism of this metamorphism.
\end{abstract}

\section{INTRODUGTION}

Sun crust is a thin, glittering ice layer which sometimes forms on the surface of a snowpack on sunny days in winter. Seligman (1936) defined sun crust as a type of snow which has been superficially melted by heat and refrozen into a crust, like a firn-snow lying above softer snow. From his observations of film crust formed on the edge of a rock or a snow mound on a calm hot day, he defined film crust as a layer of very thin ice found on top of hard snow but separated from it by a small air space. LaChapelle (1969) classified sun crust as firnspiegel, a German word meaning "firn mirror". He suggested that sun crust was formed by cold air, radiation cooling and evaporation, all working together to chill the snow surface while sunlight passed through to cause melting in the sub-surface snow layers. The meltwater from snow is refrozen at the surface and forms a thin layer of clear ice. The new "International Classification for Seasonal Snow on the Ground" (Colbeck and others, 1990) classifies sun crust, film crust and firnspiegel as sun crust.

Ozeki and Akitaya (1996) observed sun-crust formation in Hokkaido, Japan. The sun crust observed in their study was a thin ice layer, which was $1-2 \mathrm{~mm}$ in thickness and composed of ice particles with cavities formed beneath it.

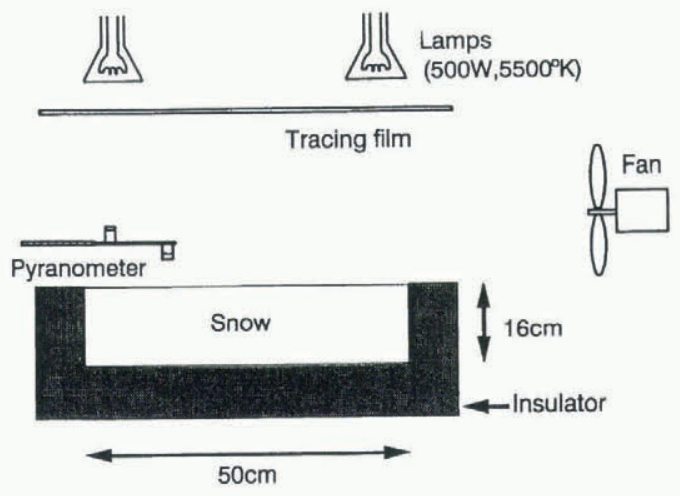

Fig. 1. Schematic diagram of apparatus 1.
In particular, they clarified the energy balance. Longwave radiative flux and latent-heat flux cooled the snow surface but beneath the surface, shortwave radiation was absorbed and internal melting occurred, giving rise to cavities. They suggested the longwave radiation refroze some of the meltwater which remained within the layer near the surface and a thin ice layer was formed.

As mentioned above, there have been few quantitative studies of sun-crust formation due to the difficulty of direct observation. In this study, the mechanism of sun-crust formation is investigated by laboratory experiments. The energy balance and water movement are also discussed.

\section{EXPERIMENTS}

The conditions for sun-crust formation were investigated by laboratory experiments. Two experimental apparatuses were set up in a cold wind tunnel at the Institute of Low Temperature Science, Hokkaido University.

\section{Apparatus 1}

A schematic view of the apparatus used for experimental runs $1-11$ is shown in Figure 1. A snow block with dimensions of $45 \mathrm{~cm} \times 50 \mathrm{~cm} \times 16 \mathrm{~cm}$ was covered with an insulator except for the upper side. Dual photoreflector lamps were used with tracing paper to reproduce solar radiation. Since the brightness temperature of the lamp was $5500 \mathrm{~K}$, the shortwave radiation from the light source had a spectrum similar to that of solar radiation. In order to enhance the transport of sensible heat and latent heat to and from the snow surface, the whole apparatus was housed in a small wind tunnel (approximately $58 \mathrm{~cm} \times 72 \mathrm{~cm} \times 30 \mathrm{~cm}$ ). Thus, both sensible- and latent-heat fluxes were the only heat sinks acting on the snow surface. The air temperature in the cold room was maintained at about $-5^{\circ} \pm 4^{\circ} \mathrm{C}$. Pyranometers were used to measure the incoming and outgoing shortwave radiation. Relative humidity was measured by a static electric-capacitance hygrometer at a height of $2 \mathrm{~cm}$ above the snow sur- 


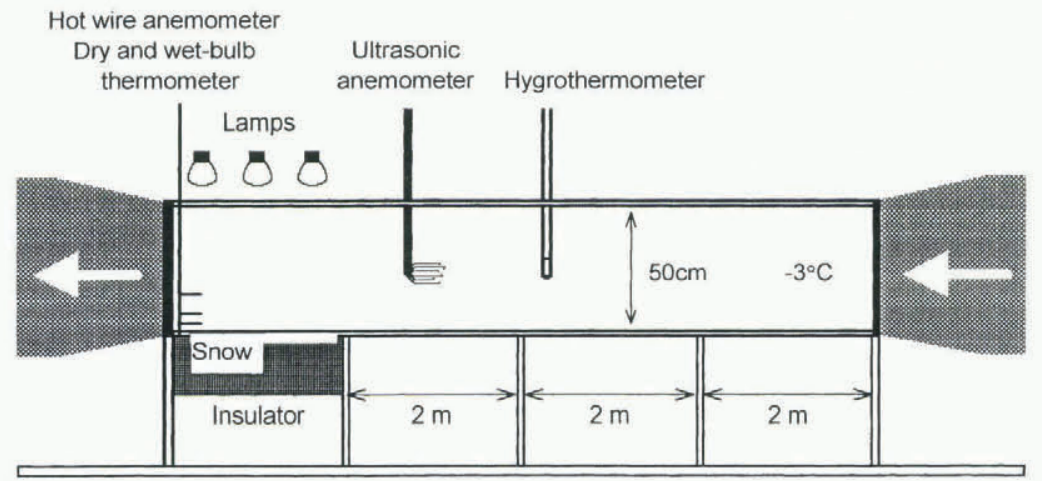

Fig. 2. Schematic diagram of apparatus 2.

face. Vertical wind-velocity profiles in the wind tunnel were measured with a hot-wire anemometer. All measurements were made on or above the snow $40 \mathrm{~cm}$ downstream from the edge of the snow. All the data were recorded by a datarecording system.

\section{Apparatus 2}

Apparatus 2 was set up in order to make experiments under conditions which minimized the heat-transfer fluctuations. The air temperature of apparatus 1 , which was set up in small cold room, fluctuated between $-9^{\circ}$ and $-1^{\circ} \mathrm{C}$ due to the radiation of the lamps. The air temperature at the center of apparatus 2 was maintained at about $-3^{\circ} \pm 1^{\circ} \mathrm{C}$. A schematic view of the apparatus used for experimental runs 12-26 is shown in Figure 2. The experiments were performed in a cold wind tunnel. It is a closed-circuit wind tunnel situated in a large cold laboratory. The working section is $50 \mathrm{~cm} \times 50 \mathrm{~cm}$, and up to $8 \mathrm{~m}$ in length is available depending on experimental requirements. A box with an open top, in which the snow sample with dimensions of $65 \mathrm{~cm} \times 50 \mathrm{~cm} \times 10 \mathrm{~cm}$ was kept, was placed at the end of the working section as shown in Figure 2. The walls of the box were lined with a heat-insulating material. A windward part on the wind tunnel's floor of $65 \mathrm{~cm}$ in length was covered by snow. The surface of the snow sample was prepared as smoothly as possible.

Six photoreflector lamps (brightness temperature: $5500 \mathrm{~K}$ ) were used with tracing paper to reproduce solar radiation. Pyranometers were used to measure the incoming and outgoing shortwave radiation. The negative heat source for the snow surface was the sensible- and latent-heat transfers. Relative humidity was measured with a hygrometer at mid-height in the tunnel. The reference wind velocity of the tunnel was measured with a micro-ultrasonic anemometer, with a probe span of $5 \mathrm{~cm}$ and a time resolution of $20 \mathrm{~Hz}$. The anemometer was installed along the center line and at mid-height of the tunnel. In addition, vertical profiles of wind velocity, air temperature and water-vapor pressure were measured over the snow surface. The profile of wind velocity was measured with a hot-wire anemometer. The temperature and water-vapor pressure profiles were observed with three pairs of copper-constantan thermocouples, $0.2 \mathrm{~mm}$ in diameter, which consisted of dry and wet bulbs. Snow-surface temperatures were measured with a thermistor sensor. The light was turned off during the measurements of the temperature profile, in order to avoid the effect of radiation. All of these measurements were made on or above the snow at $110 \mathrm{~cm}$ downstream from the edge of the snow as illustrated in Figure 2. All the data were recorded by a data-recording system.

\section{Estimation of heat flux}

Empirical formulae of sensible-heat transfer and latent-heat transfer over a melting snow surface have been obtained by Ishimoto and Kojima (1973) using the wind tunnel shown in Figure 2. These are expressed as follows :

$$
\begin{aligned}
& Q H=9.1 V_{2} T_{2} \quad\left(\mathrm{~W} \mathrm{~m}^{-2}\right) \\
& Q E=1.8 V_{2}\left(e_{2}-e_{0}\right) \quad\left(\mathrm{W} \mathrm{m}^{-2}\right)
\end{aligned}
$$

where the rate of sensible heat $Q H$ and latent heat $Q E$ are related to the air temperature $T_{2}\left({ }^{\circ} \mathrm{C}\right)$, wind speed $V_{2}$ $\left(\mathrm{m} \mathrm{s}^{-1}\right)$, and water-vapor pressure $e_{2}(\mathrm{hPa})$ at a height of $2 \mathrm{~cm}$ above the snow surface, as well as to the water-vapor pressure $e_{0}$ at the snow surface.

\section{Characteristics of the energy balance}

Twenty-six experiments were carried out, changing both the snow type and the snow density, as well as the conditions for the heat transfer. The bulk density of the snow sample was $3.5 \times 10^{2}$ to $5.2 \times 10^{2} \mathrm{~kg} \mathrm{~m}^{-3}$, which is within the ordinary range observed for old coarse-grained snow during the snowmelt season and the diameter $d$ of the snow particles was $1 \mathrm{~mm}<d<2 \mathrm{~mm}$. The snow samples were carried from a natural snowpack in Sapporo. The experiments were started after the temperature of the snow sample was considered to have corresponded to the room temperature. The intensity of the shortwave radiation was controlled by adjusting the number of lamps and was fixed during each experiment. On the other hand, the surface cooling rate was controlled by the wind speed, thus varying both latentand sensible-heat transfer.

A sun crust was formed in eight out of the 26 experimental runs. A picture of the sun crust formed in the experiments is shown in Figure 3. The surface grains bonded to each other, forming a sun crust within the duration of the experiments which lasted from 2 to 5 hours. The structure of the sun crust was the same as that observed in the field (Fig. 4): an ice layer of approximately $1 \mathrm{~mm}$ in thickness formed over cavities which were due to internal melting under the sun-crust layer.

The energy balance during the formation of sun crust was calculated. A comparison of the absorbed shortwave radiation and cooling by the sensible- and latent-heat fluxes is shown in Figure 5. Under what conditions a sun crust formed is indicated by the solid circles, the error bars corresponding to the standard deviation of the measurements. A sun crust was formed when the sum of latent-and sensibleheat flux lay between -50 and $-100 \mathrm{~W} \mathrm{~m}^{-2}$ and the absorption of shortwave radiation exceeded $200 \mathrm{~W} \mathrm{~m}^{-2}$. 


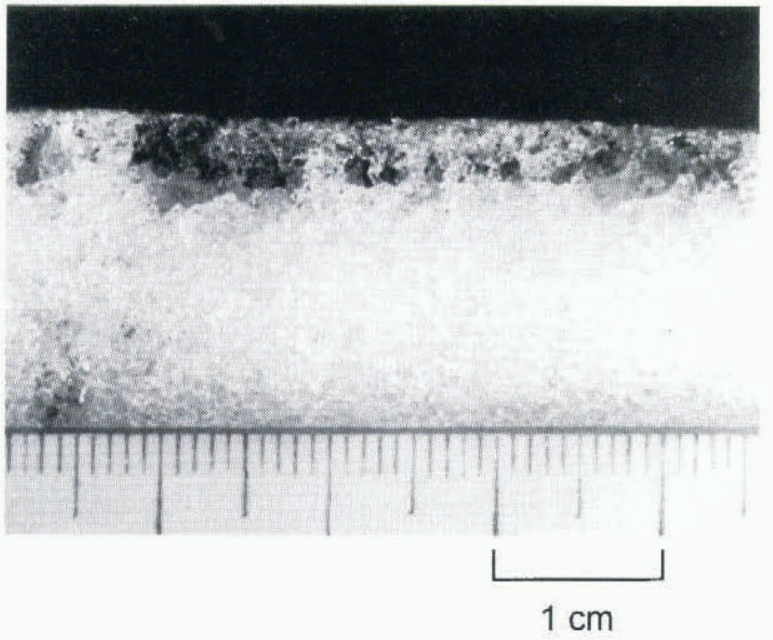

Fig. 3. Vertical cross-section of a sun crust produced in the wind tunnel under controlled conditions.

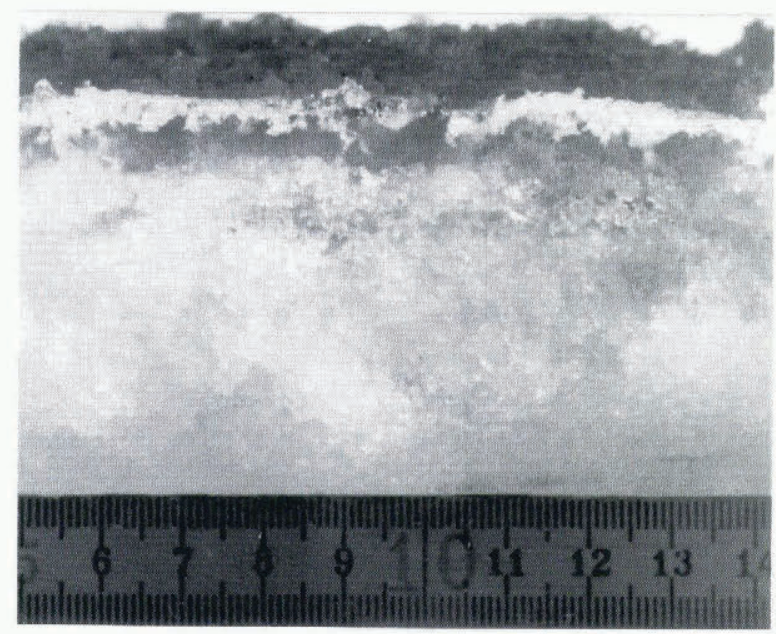

Fig. 4. Vertical cross-section of a natural sun crust.

On the other hand, runs for which the snow surface melted and a sun crust did not form are shown as open squares. Their ordinates indicate insufficient surface cooling and melting at the snow surface.

The open triangles indicate the experimental runs for which the snow near the surface did not metamorphose into an ice layer. In these cases, internal melting was not observed beneath the surface. Furthermore, either the absorbed shortwave radiation was lower or the cooling rate was larger than for the cases for which a sun crust was formed.

\section{DISCUSSION}

\section{Comparison with the observations}

The above results are compared with the field data of Ozeki and Akitaya (1996). In Figure 6, the solid circles indicate the experimental data shown in Figure 5, whereas the crosses indicate the field data averaged for each sun-crust formation. The heat balance for the sun-crust formation obtained by the experiments is, on the whole, consistent with that obtained from field observations. However, we can see that a sun crust may be formed with less shortwave absorption in the laboratory than in the field. This is probably because the experiments were sometimes carried out under suitable conditions for longer periods of time, as observed in the field.

The open squares in Figure 6 indicate the experimental data when the snow surface melted. During these experi-
- sun crust $\square$ surface melting $\Delta$ frozen surface

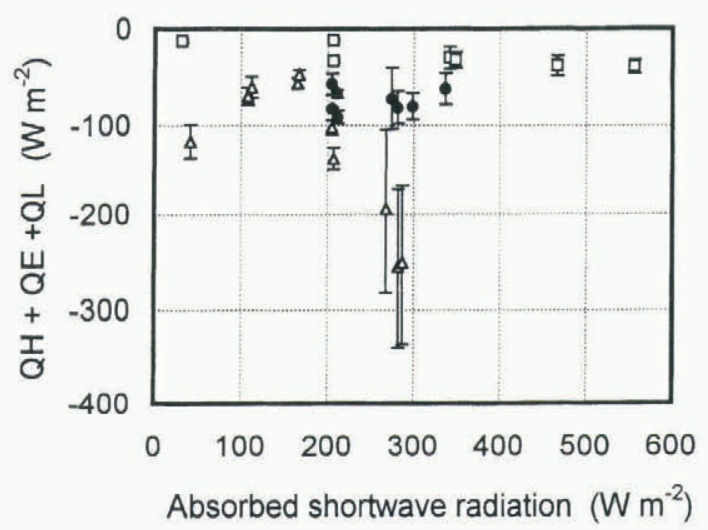

Fig. 5. Comparison of absorbed shortwave radiation and the total of sensible heat $Q H$ and latent heat $Q E$.

- sun crust $a$ surface melting $\Delta$ frozen surface + field data

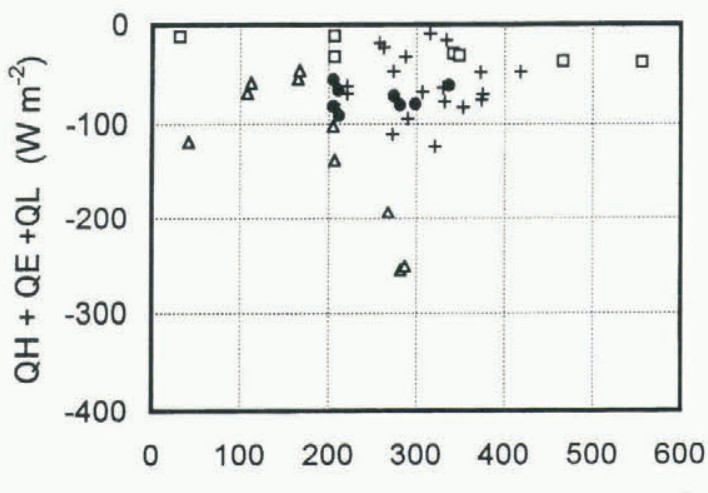

Absorbed shortwave radiation $\left(\mathrm{W} \mathrm{m}^{-2}\right)$

\section{Fig. 6. Comparison of experimental and observational data.}

ments, the snow surface tended to be rough. This is probably because both sensible- and latent-heat fluxes were the only heat sinks acting on the snow surface. The concave area of the surface, where sensible and latent heat were weak, was melted by shortwave radiation more than the convex area and the surface became rough even under the suitable energy balance for sun-crust formation.

\section{Sources of $\mathrm{H}_{2} \mathrm{O}$ for sun-crust formation}

The sources of $\mathrm{H}_{2} \mathrm{O}$ for sun-crust formation was investigated through changes in $\delta^{18} \mathrm{O}$ in sun-crust formation, using data obtained in the field and from laboratory experiments. Water supply to the surface snow layer must be considered because surface snow, the bulk density of which was approximately $4 \times 10^{2} \mathrm{~kg} \mathrm{~m}^{-3}$, metamorphosed into an ice layer during the sun-crust formation. Generally, the concentration of a heavy stable-isotope ${ }^{18} \mathrm{O}$ changes with phase changes (evaporation or condensation) and depends on the temperature of the phase change (Dansgaard and others, 1973). The oxygen-isotopic composition can be expressed in terms of $\delta^{18} \mathrm{O}$ as :

$$
\delta^{18} \mathrm{O}=\frac{R-R_{\text {SMOW }}}{R_{\text {SMOW }}} \times 1000
$$

where $R$ is the isotopic ratio $\left(\mathrm{H}_{2}{ }^{18} \mathrm{O} / \mathrm{H}_{2}{ }^{16} \mathrm{O}\right)$ of the sample and $R_{\text {smow }}$ is the isotopic ratio of Standard Mean Ocean Water.

Two processes for $\mathrm{H}_{2} \mathrm{O}$ supply are conceivable. One is the condensation of water vapor. During sun-crust formation, the snow surface is chilled by radiative cooling and evaporation, while the local temperature beneath the sur- 
face rises and internal melting occurs. Thus, a vapor-pressure gradient may cause the water vapor to be transported from the lower melting layer to the crust layer. Sato and Watanabe (1985) conducted experiments to investigate the $\delta^{18} \mathrm{O}$ profile in snow with a temperature gradient and proposed a model. According to their results, under the conditions that the upper side with a cap, such as an ice crust or ice lens, is colder than the lower, the $\delta$ value of the upper snow becomes smaller (lighter water) than that of the lower snow.

The other possible process for $\mathrm{H}_{2} \mathrm{O}$ supply is the refreezing of liquid water in the crust layer. In this process, internal melting makes cavities which act as an impermeable layer under the surface, the meltwater remains within the layer near the surface due to capillary force and refreezes due to negative heat fluxes at the surface. The isotopic composition of the solid and liquid parts of the wet snow changes during grain coarsening; $\delta^{18} \mathrm{O}$ of ice becomes larger than that of water (Nakawo and others, 1993). In addition, the dropping of liquid water has often been observed during sun-crust formation and, therefore, it is possible that the lighter residual liquid water drops out from the sun-crust layer, making the layer heavier. In this case, the $\delta$ value of the upper snow should be larger (heavier water) than that of the lower part.

In this study, samples were taken from the crust layer and the snow layer of $1 \mathrm{~cm}$ in thickness beneath the crust both in the field and the laboratory experiments. Changes in the $\delta^{18} \mathrm{O}$ profile near the surface snow and changes in the sun crust with time were investigated.

A comparison of the ${ }^{18} \mathrm{O}$ content of the sun crust and the snow layer beneath it is shown in Figure 7. The $\delta^{18} \mathrm{O}$ in the snow layer is distributed between -9.3 and $-13.6 \%$. On the other hand, $\delta^{18} \mathrm{O}$ in the sun crust is distributed between -4.7 and $-12.5 \%$. Furthermore, the $\delta$ value of sun crust was larger (heavier water) than that of the snow beneath it.

The heat transfer from the atmosphere to a crust surface is calculated for both cases, i.e. water-vapor condensation and refreezing of liquid water. When the snow metamorphoses into an ice layer ( $1 \mathrm{~mm}$ in thickness) by condensation of water vapor, the latent heat due to the condensation is estimated to be $1.5 \times 10^{6} \mathrm{~J} \mathrm{~m}^{-2}$. On the other hand, the average cooling rate of the snow surface, estimated from field observations, was $-61 \mathrm{~W} \mathrm{~m}^{-2}$ during sun-crust formation. This means that about 7 hours are necessary for the sun crust to be formed. Since field observations show that sun crust usually forms in less than 6 hours, it seems reasonable to suppose that water-vapor condensation is not important for sun-crust formation.

Considering the case of $\mathrm{H}_{2} \mathrm{O}$ being supplied by the refreezing of liquid water, it requires $1.7 \times 10^{5} \mathrm{~J} \mathrm{~m}^{-2}$, which is one order smaller than the heat of condensation. Taking into account the above cooling rate in the field, metamorphism by refreezing needs only 1 hour. Thus, it is fairly certain that the refreezing of the meltwater makes the sun crust. As a result of the changes in $\delta^{18} \mathrm{O}$ and the heat-transfer calculation, we may conclude that refreezing of liquid water is the dominant mechanism in this process.

\section{GONCLUSIONS}

The energy balance of sun-crust formation has been clarified through laboratory experiments in a cold wind tunnel. Intense shortwave radiation and snow-surface cooling have been reproduced in the laboratory. The experiments were

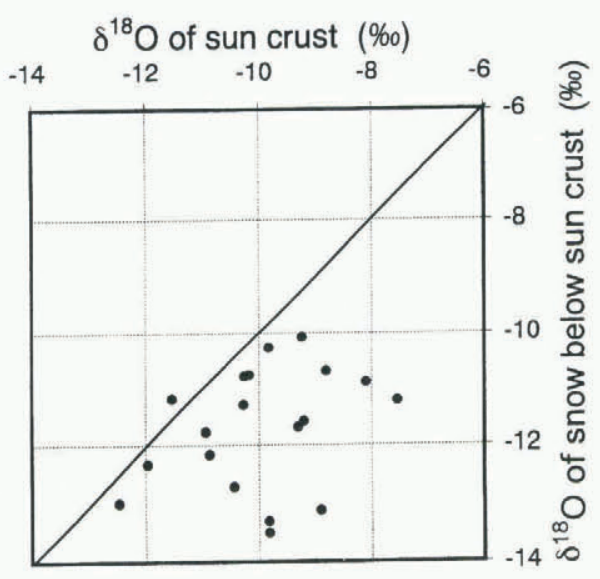

Fig. 7. Comparison of $\delta^{18} \mathrm{O}$ in the sun crust and the snow beneath it.

carried out by changing the heat conditions and the sun crust formed was consistent with that observed in Nature. The surface-cooling rate was between -50 and $-100 \mathrm{~W} \mathrm{~m}^{-2}$, and the absorption of shortwave radiation exceeded $200 \mathrm{~W} \mathrm{~m}^{-2}$. The energy balance during the formation of the sun crust agreed with the data observed in Nature.

The sources of $\mathrm{H}_{2} \mathrm{O}$ for the sun-crust formation were investigated through changes in $\delta^{18} \mathrm{O}$ both in the field and in laboratory experiments. Since the $\delta$ value of sun crust was larger (heavier water) than that of the snow beneath it, it was concluded that the refreezing of meltwater was the dominant mechanism in this metamorphism. This was also supported by the calculation of latent-heat emission with the formation of the sun crust. We therefore argue that the rise in meltwater up to the snow surface by capillary attraction and refreezing in the thin layer near the surface are key processes for sun-crust formation.

\section{ACKNOWLEDGEMENTS}

The authors are grateful to K. Kikuchi of the Faculty of Science, R. Naruse and N. Ishikawa of the Institute of Low Temperature Science, Hokkaido University, for their useful suggestions, and K. Nishimura for his valuable comments. The authors are also indebted to K. Suzuki of the Faculty of Science, Shinsyu University, for his support in the $\delta^{18} \mathrm{O}$ analysis of sun crust.

\section{REFERENGES}

Colbeck, S. C. and 7 others. 1990. The international classification for seasonal snow on the ground. Wallingford, Oxon, International Association of Scientific Hydrology. International Commission on Snow and Ice.

Dansgaard, W., S.J. Johnsen, H. B. Clausen and N. Gundestrup. 1973. Stable isotope glaciology. Medd. Gronl., $197(2), 1-53$.

Ishimoto, K. and K. Kojima. 1973. [Wind tunnel experiments on snow melt due to sensible heat transfer from the atmosphere] Low Temp. Sci., Ser. A 31, 143-157. [InJapanese with English summary.]

LaChapelle, E. R. 1969. Field guide to snow crystals. Seattle, WA, University of Washington Press.

Nakawo, M., S. Chiba, H. Satake and S. Kinouchi. 1993. Isotopic fractionation during grain coarsening of wet snow. Ann. Glaciol., 18, 129-134.

Ozeki, T. and E. Akitaya. 1996. Field observations of sun crust formation in Hokkaido, Japan. Arct. Alp. Res., 28(2), 244-248.

Satow, K. and O. Watanabe. 1985. Net accumulation and oxygen isotope composition of snow on Mizuho Plateau, Antarctica. Ann. Glaciol., 6, $300-302$.

Seligman, G. 1936. Snow structure and ski fields. London, Macmillan. 